\title{
Community Perceptions and Experiences on the Events Leading to Facility Maternal Death; A Verbal Autopsy Qualitative Study
}

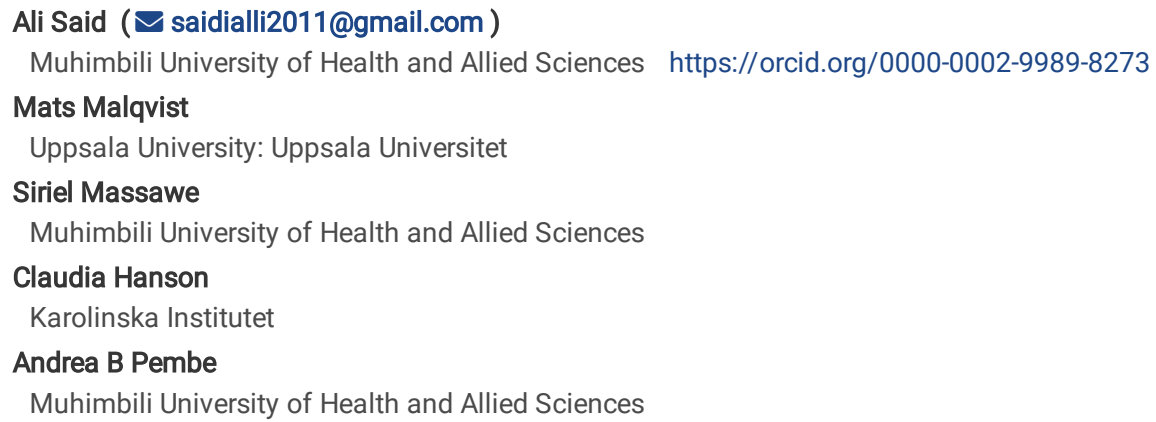

Research

Keywords: Maternal Death, Maternal Mortality, Community perceptions, Community experiences, Birth preparedness, Caregivers, miscommunication in health care

Posted Date: April 6th, 2021

DOI: https://doi.org/10.21203/rs.3.rs-361674/v1

License: @ (i) This work is licensed under a Creative Commons Attribution 4.0 International License. Read Full License 


\section{Abstract}

\section{Background}

Tanzania Maternal Death Surveillance and Response (MDSR) system introduced in 2015 emphasizes review of facility maternal deaths with little community involvement. Involving the community in deaths enquiry can help to make better strategies to prevent future deaths. We aimed to explore family members (caregivers) perceptions and experiences on the events leading to facility maternal deaths to inform future community involvement in MDSR

\section{Methods}

Narrative interviews were conducted with 20 caregivers who cared for women who died in childbirth to investigate into delays and health care seeking experience. The unstructured questions on perceptions and experiences of events leading to death were administered together with standard verbal autopsy questionnaire. Two regions, Lindi and Mtwara of Southern Tanzania were selected for the study in 2018. Narrative thematic analysis was used for data analysis.

\section{Results}

Three main themes evolved: 'Prepared for birth but not ready for complications', 'Disconnect between caregivers and providers' and 'The bitter impact of maternal deaths'. Caregivers made efforts to prepare for birth but their preparation were severely inadequate when complications that necessitated referral occurred. Decision to seek care was made jointly between the pregnant woman, husband and other family members. Caregivers tried with little success in communicating with heath providers regarding their admitted patients. They also experienced emotions of grief such as denial, anger, depression, bargaining and acceptance once maternal deaths occurred. Caregivers (mostly old women) were left with the burden of caring for the newborns and other children left by the deceased mother.

\section{Conclusion}

Caregivers

perceptions and experiencesofmaternaldeathseventsprovvaluab $\leq \in f$ or mationf or compnity $\int$ erventionsonbirthprepared $\neq$ ss, decision accountability. Maternal deaths bring far reaching mental, social and economic consequences to the family and society

\section{Plain English Summary}

Maternal death surveillance and response is a system implemented mostly in low-and middle income countries that have high maternal mortality inorder to learn lessons for improvement of quality of care. The system relies on information and inclusion of community members to understand events surrounding maternal deaths. We interviewed family members who were taking care of pregnant women from pregnancy period to delivery and death in health system. We aimed to describe their perceptions and experiences of events surrounding maternal deaths.

Family members believed they were prepared for birth but their preparations were not adequate. When complications of pregnancy occurred families struggled to mobilize resources to help the pregnant woman. While admitted in hospitals, family members were unable to obtain information from health providers due to poor communication. The occurrence of maternal deaths causes financial, psychological and social problems to the family.

In conclusion, family members can provide useful information in efforts to reduce maternal deaths in health systems

\section{Background}

Worldwide Maternal Mortality Ratio (MMR) is still high despite numerous efforts to improve quality of care for deaths reduction. The burden is disproportionately higher in-low and middle-income countries (LMICs) such as those in sub Saharan Africa and South East Asia [1]. Maternal mortality is one of the indicators of quality of health care for pregnant women. The Millennium Development Goal 5 (MDG5) aimed at reducing global maternal deaths by $75 \%$ by the year 2015 [2]. Few countries have accomplished that goal, but during that period South East Asia has seen more reduction of maternal deaths than other LMICs. In Eastern Sub-Saharan Africa maternal mortality trends have been decreasing at a rate of $4.5 \%$ a year since 2005 [3]. Tanzania with one of the highest MMR in sub Saharan Africa [1, 4] has put forward a strategic plan to achieve the Sustainable Development Goal 3 (SDG3) of reducing global MMR to less than 70 per 100,000 live births by the year 2030 .

In 2015, Tanzania introduced the Maternal Death Surveillance and Response (MDSR) system [5] as recommended by the World Health Organization (WHO). Through the system, lessons are learnt by identifying and reviewing deaths to improve quality of care and prevent future similar deaths [6].The WHO recommends community involvement in the MDSR system through Verbal Autopsy (VA) or Social Autopsy (SA) to enhance learning from deaths. However this has not been introduced in Tanzania. In these methods a standardised questionnaire is used to interview relatives or caretakers and sometimes neighbours to investigate the circumstances of the deaths [6-9]. The information obtained is analysed to understand causes and contributing factors of maternal deaths from outside facilities. These methods can lead to increased community dialogue, community knowledge, reflection, empowerment, increase community commitment, health care seeking behaviour and stakeholder participation[10]. In general, the information from community interviews and dialogues can complement facility review to get a clear understanding about the cause and contributing factors to deaths [6, 11, 12]. In Bangladesh, for example, communitybased review using VA and SA mobilized the community to take part in activities to reduce maternal and perinatal deaths. These included change of community behavioural pattern and engagement of community to strategized ways to prevent maternal deaths[13, 14]. In Indonesia, verbal autopsy with palativac of tho danascad ravaalad thair undarstanding of causes of deaths based on the culture and behaviour toward health seeking [15], while in Nigeria Loading [MathJax]/jax/output/CommonHTML/jax.js 
community perceived maternal deaths to be due to deficiencies in care provision, traditional health care seeking and providers negligence [16-18]. Understanding what the community perceives as causes can help their integration into the MDSR system.

However, there is little understanding on how community and family members perceive the chain of events leading up to maternal deaths at health facility. Most studies have been done to community members in general and there are few studies on members who recently cared for the woman who died in connection to pregnancy or child birth. There is also a need to describe how community members experience the interaction with healthcare providers once the patient is in the health system. Therefore we aimed to explore how caregivers perceived and experienced events preceding maternal deaths, from home to health facility. Understanding these experiences will provide information for action in community based reviews and help shape provider-family interactions in the process of caring for pregnant women.

\section{Methods}

\section{Study design}

This was an analysis of narrative interviews conducted through standard verbal autopsy questionnaire complemented by an open question for a study intended to compare cause and delays in care between an expert panel and the MDSR system in Tanzania[19]. The VAs were conducted between March and April 2019 among family members who cared for women who died from maternal deaths in health facilities between January $1^{\text {st }}$ and December $31^{\text {st }} 2018$.

\section{Study Setting}

The study was conducted in Southern Tanzania in Lindi and Mtwara regions. The two regions were selected because they are representative of the health structure of Tanzania. Also they have high facility delivery rates, high maternal mortality and most maternal deaths occur in health facilities. The total population for the two regions is approximately two million people [4, 20]. In 2018, a total of 122 facility and 10 community maternal deaths were reported from both regions [19]. The facility maternal deaths occurred in two regional hospitals, eight district hospitals, three mission hospitals, nine health centres and two dispensaries. Maternal deaths are usually reported from the facility to district then to the regional health office through the Regional Reproductive and Child Health Coordinators (RRCHCOs). Community maternal deaths are not routinely and identified, notified or reviewed. Facility maternal death reviews little or no inclusion of family and community perspectives

\section{Sampling of participants}

This study was done as part of another larger study which involved performance of VA interviews for 106 facility maternal deaths from both regions. After the VA quota sampling was used to select narrative interviews for analysis of this study. Interviews were selected from both regions on basis of their richness in data (15 minutes or more of interview duration). We also selected on basis of residence (urban and rural), husbands, mothers, grandmothers and other relatives who cared for the deceased. Data saturation during analysis was the basis for the final sample selected during analysis. We started to notice data saturation after 16 transcripts were analysed, but we continued to 20 transcripts. Further reading of other transcripts did not reveal new findings. Analysis was done for interviews of nine husbands, six mothers, two grandmothers and one sister, aunt and uncle. All were caregivers who cared for the deceased women from pregnancy to death in health facilities.

\section{Data collection}

The first author (AS), working with RRCHCOs of both regions, gathered demographic information (name, age, date of death, facility of death, referring facility, facility of antenatal care attendance, region, district and village/street of residence, name of male partner and name of village/street leader) for each facility maternal death in medical records. These were mostly done at the regional health office during the planning stage and others were identified during field activities in the districts. The field team (AS and two interviewers) then traced families using demographic information for VA interviews. The process of tracing families for interviews was done by first enquiring in the health facility where the deceased woman died or attended antenatal clinic. The field team was then directed to the family either directly or through local government leaders. Each family was visited with the help of a healthcare provider or a local government leader to introduce the field team. After introducing the field team, family members were explained the purpose of the visit and the VA. The persons that were helping the deceased (caregivers) during pregnancy, illness and death were identified, and then one of the interviewers conducted the interview with them.

Verbal autopsy interviews were conducted using the translated standard questionnaire provided by WHO [21]. In addition, we added six questions with probes for the respondent (caregiver) to narrate their experiences in caring for the deceased from pregnancy and delivery to death. These were open ended questions for the respondents to narrate events that occurred from time of pregnancy, delivery and after delivery at home, on the way to facility and at health facility. Then there was a question on what they thought was the cause of death. They were also asked to explain issues on recognition of the problem (who, when and how it was recognised) and health care seeking process (who, when and how decision was made), thus build on the three delay model[22]. Furthermore, question of their perception on delays encountered in health care seeking, finding and paying for transport and delays encountered once they reached health facilities. Probes were used to be more specific for identification of delays. Then the interviewers continued asking other standard VA questions.

\section{Data analysis}

The narrative recordings were transcribed by verbatim method. Analysis was done using narrative thematic analysis inspired by Butima [23]. This was done in the following steps; i) Organising and preparing data by verbatim transcription, and few editing to remove unnecessary words such as 'mmh' and 'yes', mostly from the interviewer; ii) Getting general idea of data by reading through line by line during organisation and editing. During this stage some themes were

Loading [MathJax]/jax/output/CommonHTML/jax.js 
identified; iii) Coding the data manually; iv) Identifying categories from the codes; v) Re-organising the categories to make sub themes and themes; v) Interpreting the data.

Data validation and verification was inspired by Creswell [24] by having other authors go through the interview transcripts and the results, giving their opinions on whether the analysis was based on the data. Furthermore, as a process of verification for trustworthiness, the VA interviewers were asked to look at the final results for validation. Due to difficulties in retracing the family, respondents (caregivers) were not included in this procedure. We also ensured reliability by describing details of data collection and analysis process. The selected interviews for analysis were of respondents from different residence (rural and urban areas) in both regions and different respondents such as mothers, husbands and grandmothers. Data saturation was the basis used to decide the final number of respondents to be selected for analysis.

\section{Results}

Analysis of data yielded 3 main themes with 6 subthemes and several categories. The themes were: Prepared for birth but not ready for complications, Disconnect between caregivers and providers and The bitter impact of maternal deaths. The subthemes were: Basic birth preparation and care seeking routines, Inadequate resources for complications (Under Prepared for birth but not ready for complication); Caregivers failing to connect to health system, Providers creating communication gap (Under Disconnect between caregivers and providers); Going through grief stages, Precarious fate of newborn (Under The bitter impact of maternal deaths) (See table 1)

Table 1: Theme, subtheme and categories from the interviews

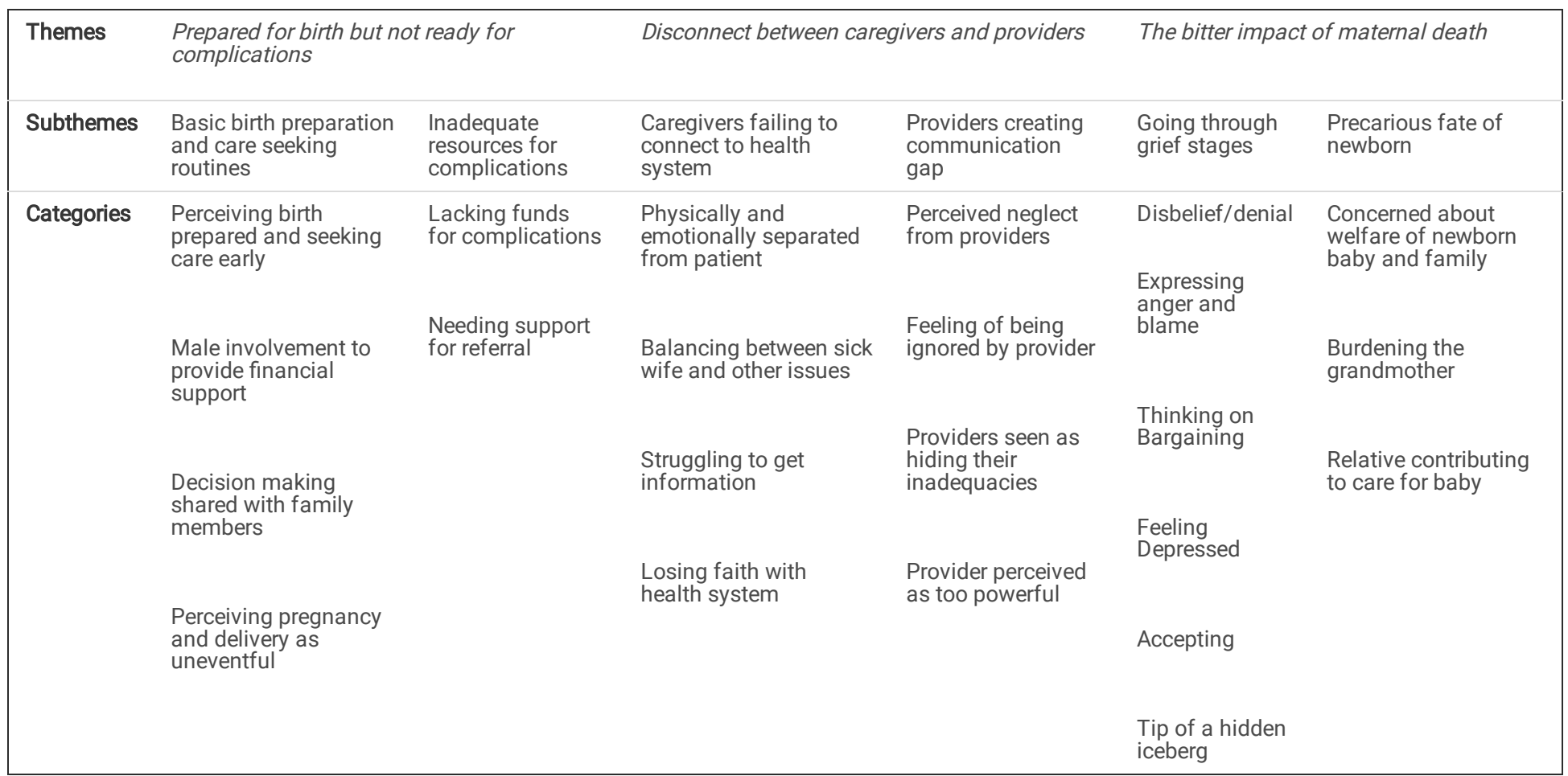

\section{PREPARED FOR BIRTH BUT NOT READY FOR COMPLICATIONS}

This theme explains dynamics in the family on issues of birth preparedness and health care seeking. Family members who were caring for the pregnant women explained their practice of birth preparation. However, once the pregnancy or birth process was complicated requiring referral and long hospital stay, the birth preparations were seen as inadequate. Occurrence of complications then stretched family resources to the limit and led to delays that contributed to deaths. They also explained how the decision to seek care was made within the family, involving different family members

\section{Basic birth preparations and care seeking routines}

Caregivers described how they prepared for birth by doing different things such as preparing money, transport, someone to escort the woman and some supplies (birth kit). Deliberate efforts were made by caregivers to find resources for birth preparation. Decision to seek care was also described to have been taken early, even though it was clear some decision-making processes created delays.

... I did some hustling and made about 300,000tshs and put it aside inorder to prepare and attend to health care during birth... (Husband of the deceased)

... first we did not have problems with transport, because he had prepared money (for transport) and motor cycle was available... (Aunt of the deceased)

The male partner was described both by men themselves (husbands) and other caregivers to play a key role in preparation of financial resources for birth. This was the case even when the man was away from home; he was called to arrange for transport and funds to seek care in health facilities. Men also provided Loading [MathJax]/jax/output/CommonHTML/jax.js nt in hospital and other caregivers who travelled with the pregnant woman. 
...We called him, and we told him your wife has started labour, and we are getting prepared to take her to hospital: He called his friends and they brought a car, we seated in the car and we went to the hospital... (Grandmother of the deceased)

Decision making on when and where to seek care was made through consultations in the family, mostly to elderly women or men. Caregivers, especially men, had to ask women such as mothers or grandmother when labour started whether it was time to seek care. The consultations sometimes took time since they had to wait for someone to come from another village or patient travelling to that village for care or for consultation. These consultative plans are not done in advance and therefore caregivers did not seem to think this created delay to seek care.

... we lived in different places... when she started labour at night, her fiancé (male partner) came here to call me and told me I think labour has started. I went there and found its true labour has started... we took motor cycle to the hospital... (Aunt of the deceased)

Caregivers also explained how they thought that the pregnancy period of the deceased was uneventful since the pregnant woman did not experience any problems during pregnancy. Others explained that they did not expect problems since other pregnancies and deliveries had been uneventful. This influenced how they prepared for birth and where they decided to seek care.

... we went to the health centre... since she delivered without problems, even second pregnancy she delivered without problems, and the third pregnancy she said she delivered without problems... (Husband of the deceased)

\section{Inadequate resources for complications}

Even though family members (caregivers) explained that they did birth preparations, it was evident that their preparations were not adequate once complications started. When a pregnant woman needed to be referred from initial facility of care, family members struggled to come up with financial resources to support themselves and the patient. They had to borrow money, ask other relatives to contribute or sell their own property to meet the financial needs.

... But at the same time I had already asked for financial help, I was preparing to transfer the patient to another facility. I was supposed to get the money that day of Wednesday (the day she died)... (Husband of the deceased)

\section{DISCONNECT BWETEEN CAREGIVERS AND PROVIDERS}

This theme describes perceptions and experiences of caregivers on communication with health care providers (nurses and doctors) once the patient was admitted in the facility, especially in hospitals. Once the pregnant woman was admitted in the hospital, caregivers had problems accessing the patient or getting information about the issues that were happening. Caregivers made efforts to communicate with providers to get information about their loved one, but this was inadequately reciprocated by the health care providers. This created frustration among caregivers and led to efforts to change places of care.

\section{Caregivers failing to connect to health system}

Family members who cared for the deceased and travelled with her to the facility perceived the ward to be a barrier which separated them from their patient. This was coupled with little or lack of information from the health system about the patient.

... even if you go (to hospital) as a man you will end staying outside (the ward) inside there (you are not allowed)... you may depend on calling with phone. She will tell you if medicines have changed... (Husband of the deceased)

Caregivers also had to balance between taking care of the sick woman in hospital and other family issues such as work and children at home. This further complicated the communication with healthcare providers and affected their understanding of what was going on in the hospital.

.... so that day there was a heavy rain clouds, I was running to come home (from hospital) to wash clothes for the children... When I came here I washed and lost a lot of time... (Husband of the deceased)

Lack of communication led to the perception that the patient was not well cared for. There were some caregivers who expressed their dissatisfaction with care provided and lack of information to an extent of thinking and planning to seek care in other facilities or from traditional healers.

... Her husband arrived in the morning, so we said amah we have stayed here and she still coughing with difficulty in breathing with no treatment so it's better we go home and try local herbs because we have stayed here with no medications...(Grandmother of the deceased)

\section{Providers creating communication gap}

Caregivers also thought that providers were not paying attention to them, and not providing information despite the seriousness of the patient's illness. They felt they were excluded from the care of the woman once she was admitted in the hospital. This further created a communication gap, as caregivers were unaware of and were never told about the complications that had occurred to their loved one. Caregivers could not explain the causes of death since the healthcare providers never discussed with them what happened.

...that doctor was inside, he was busy... I did not know who to go to for explanations... the person involved (the doctor) was busy. That day ended without seeing the doctor (to ask for information)... (Husband of the deceased)

Caregivers also thought health care providers communicated less because they were hiding their shortcomings in care. They explained that health care Loading [MathJax]/jax/output/CommonHTML/jax.js on and coerced family members to provide false public statements about maternal deaths. 
... the health providers of the hospital came and told me "we want you to go there (to a public meeting) and say this and this and this". All that they told me to say were not truthful to what happened... (Husband of the deceased)

There were also instances when health care providers were perceived as harsh and had too much power. The family members could not do anything to force the healthcare providers to give information. This made caregivers feel helpless in front of providers since they were unfriendly and unapproachable.

... My patient was not feeling well... the health provider is not friendly anymore to the patient. The health provider is like a ruler in the hospital... (Husband of the deceased)

\section{THE BITTER IMPACT OF MATERNAL DEATH}

The participants expressed how the death of the woman affected them personally and their families. This spanned from the emotional turmoil they went through to the welfare of the children, and effects on the partner and the newborns that were born alive.

\section{Going through grief stages}

Once the caregivers received the news of a maternal death they expressed emotional outbursts of disbelief and sadness. For some caregivers, the emotional reactions recurred during the interviews.

I had no means, I didn't believe, I told her I don't believe, she has died... (Aunt of the deceased)

Caregivers also expressed anger and thinking of someone to blame for the death. Some even had plans of seeking for justice by suing healthcare providers for negligence.

.... Whatever happens all my blames will go to the hospital. I don't know anything about medicine but I will blame the hospital... (Husband of a deceased)

...I wanted to find a lawyer to help me get justice... (Husband of a deceased)

Others expressed how they could have changed the situation if they had made different decisions on places to seek care. Husbands especially described how they went through psychological depression as a result of losing their wives. Death was later accepted as God's plan and family members thought asking for justice was never going to change what happened.

... I did not know how to get drunk but I started drinking alcohol at home. I was coming back at midnight or more, when I came at midnight I left at 0100hrs, I could not sleep... (Husband of a deceased)

Furthermore, caregivers thought the problem of maternal deaths is big and unknown to the general public and the government. Some explained that this was not the first time they personally experienced a maternal death and that things need to be done to change the situation.

...we have been touched a lot with this tragedy. In this tragedy there are a lot of us but we have no platform to speak... (Husband of the deceased)

\section{Precarious fate of the newborn}

Family members described that the death of the mother left a live newborn in an uncertain environment. Close caregivers such as husbands, mothers and grandmothers explained how immediately after the death the thought of the newborn's welfare came into their minds.

...I said (name of the deceased) my child, this baby you are leaving to me, would I be able to handle it? She slept there at bed I said: Would I be able to handle this? If it was like clothes, I would say give me I go and you stay with the babies... (Mother of deceased)

Each family explained they had to come up with a plan to care for the newborn, but most of time the burden was left to the grandmother in the village. This responsibility of providing baby formula, clothes and healthcare was acknowledged to be difficult for the old women even if other family members contributed to the care whenever they could.

...try to imagine, grandmother in the village is only a small scale farmer, she does not know lactogen... Her daughter got pregnant but for hospital weakness she dies, will grandmother be able to care for the baby... (Husband of the deceased)

\section{Discussion}

The results of this study suggest that families and caregivers prepare for birth, but they do not go far enough to account for complications. Once the pregnant woman is admitted in the hospital there is break down of communication between caregivers and healthcare providers. The study also describes how caregivers experience emotional and social trauma from the death of a pregnant mother. These spanned from denial and anger to acceptance and acknowledging that maternal deaths is a big problem. They also explained their struggle in caring for newborn and children left by the deceased mother. In some families the burden fell on the grandmothers in the village, who had shortage of resources to care for the motherless children.

The WHO recommends and made efforts to advocate for birth preparedness and complications readiness for pregnant women. However, studies in LMICs have revealed that pregnant women and their families have different level of understanding and practice of birth preparedness and complication readiness [25-28]. In most of these settings the level of awareness was higher than the proportion of women who actually prepared for birth and complications. A Loading [MathJax]/jax/output/CommonHTML/jax.js 
complications [29]. Caregivers in our study described their birth preparations included finances, transport and people to escort the pregnant woman to hospital. They revealed that their financial preparations were inadequate once complications started, to necessitate prolonged hospital stay or referral to another facility away from their primary facility of care. Families were unable to mobilise funds fast enough to get transport for referral on time. One of the reasons for this was the families' perceptions that pregnancy was uneventful and so they might not have expected major complications during birth or after birth. Experience from uneventful previous births also affected how and where they sought care. The concept of birth preparation needs to be clear for families in order to prepare for the possibility of major complications.

These findings are in contrary to the concept of Universal Health Coverage (UHC), which emphasizes that all individuals in the community should receive timely and quality health care without financial hardships[30]. Despite Tanzania`s policy of free maternal care services, families still have to prepared money to meet the financial burden. To attain SDG3 of reducing maternal mortality ratio to less than 70 per 100,000 live births, deliberate efforts should be made to make sure UHC is available to pregnant women in Tanzania.

Decision on when and where to seek care was mostly done by the pregnant woman and the closest caregiver, such as the male partner with consultation of other family members, mainly elderly women. Even though the man was the main resource provider, his decision-making power was shared with the pregnant woman, and her mother or mother-in-law. Different societies have different family dynamics on decision-making when it comes to health care seeking. In Nepal for example, husbands were described as more influential in decision-making regarding place for antenatal and delivery care [31]. While in Rufiji Tanzania, husband and other relatives were the main decision-makers regarding referral to hospital [32]. Understanding these family dynamics provides opportunity for targeted interventions to improve health care seeking.

Communication between healthcare providers and family members has been described as important in making diagnosis and management of patients. This is because family members can provide valuable information and cooperate in caring for the patient [33]. A systematic review on communication between family members and healthcare provider highlighted the importance of providing information on condition deterioration, inclusion in decision making and providing clear and accurate information to caregivers [34]. Some of the reasons described to affect caregivers communication with healthcare providers are financial arrangements and misunderstanding of privacy rules by healthcare providers [35]. In our study, caregivers explained the difficulties in getting information about their patient once she was admitted in the ward. This was due to fact that the set-up of hospitals does not allow family members to stay with the patient in hospitals. Fear of blame by providers could also have been another reason for them to be reluctant to share progress information with family members.

Lack of respectful maternity care could also explain the break-down in communication between caregivers and providers. In Malawi communication barriers between providers and family members were due to lack of respect, language barrier and low social status of the patients [36]. In Northern Tanzania, pregnant women reported lack of respectful maternity care from providers while in labour [37]. This could be mitigated by helping providers to realize their own shortcomings and negative attitudes towards pregnant women when providing maternity care [38]. In turn, healthcare providers will come up with better strategies of informing and communicating with families and caregivers inorder to foster patient-centred care and respectful maternity care.

Maternal death is a traumatic event to the family and its effects can have far-reaching effects in society. Studies in Ethiopia, Tanzania, South Africa and Malawi on the effects of maternal deaths have reported consequences on the children's wellbeing, nutrition and schooling, as well as increased risk of child labour, family separation and economic cost to the society $[39,40]$. The male partner and children are usually the first to feel the impact of the lost mother. Family members interviewed in this study expressed a wide range of emotional trauma they went through from the moment they received news of the death. They were found to be in different stages of grief at the time of interview. Their emotional responses ranged from denial, anger to plans for seeking legal justice. Some male partners explained how they went through emotional turmoil that could have ended in clinical depression. Still there were family members who had accepted the death and moved on. The most important concern family members had was the fate of the newborn and other children. This study reports similar effects that have been described in other studies on the mental, physical and social consequences of children and other family members left by the mother. This burden was described to have been shifted to the grandmothers in the village who had limited resources to care for these children. This impact of maternal death should be highlighted to government and non-government organisations inorder to address the burden and help alleviate society from the effects.

\section{Strength And Limitations Of The Study}

The interviews were conducted among caregivers who experienced the chain of events leading up to maternal deaths. The perceptions and experiences described can thus reflect what the community and families go through when caring for woman who dies in health facilities. We did pre-training of all interviewers before interviews were done. A three-days workshop was conducted to orient interviewers on the study and the tool. This was followed by a pilot study where interviewers tested the tool in the field using real family members. During the training and piloting the tool was improved by changing translations and adding a few probes to help interviewers. Data saturation ensured we got the required number of participants for analysis. Saturation in this study was attained after 20 interviews had been analysed. In total there were 106 interview transcripts. The authors believe saturation was attained since there were no new information, however this cannot be guaranteed. Since the authors worked with the data for another study, they tried to make sure that all data that was reported in the other study were not repeated in this study. This was mostly data on the medical causes of death and the three delays identified by physician reviews. The authors' work and training in the MDSR system could also have affected their interpretation of data for this study. Several meetings were held between authors to make sure their interpretation was grounded in the data.

\section{Conclusion}


Caregivers

perceptions and experiencesofmaternaldeathseventsprovvaluab $\leq \in f$ or mationf or compnity $\int$ erventionsonbirthprepared $\neq$ ss, decision accountability. Maternal deaths bring far reaching mental, social and economic consequences to the family and society.

Complication readiness should be emphasized to family members caring for pregnant women. The health system should create supportive environment for caregivers and healthcare providers to communicate effectively during care provision. Policy and decision- makers should be made aware of the effects of maternal deaths on families and society, in order to take action. Further studies are needed to describe how community involvement in the MDSR system can be strengthened.

\section{Declarations}

\section{Ethics approval and consent to participate}

Ethical approval to conduct the study was requested and granted by the Muhimbili University of Health and Allied Sciences (MUHAS) Senate Research and Publication Committee with reference number 2017-23-07/AEC/Vol.XII/343. Permission to conduct the VA interviews was provided by the Ministry of Health Community Development Gender Elderly and Children (MoHCDGEC), the President`s Office Regional Administration and Local Government (PO LARG), Regional Medical Officers(RMOs), District Medical Officers (DMOs) and Local government offices. Participants were explained in details what was to be done, the purpose of the interview and the expected outcomes. They were further explained no physical might be inflicted on them but they might experience emotional reaction when talking about death of their loved one. All participants signed an informed consent and consented for audio recording before interview commenced. Interviews were conducted in place with audio secrecy at the respondent's home. All interviews were anonymized by coding them, stored in safe location and keys kept by the first author alone. The audio recordings and transcripts are kept by the first author in lock and key and computer depository respectively.

\section{Consent for publication}

Not applicable

\section{Availability of data and materials}

The dataset generated and analyzed during the current study is available from corresponding author upon request

\section{Competing interests}

The authors declare that they have no competing interests

\section{Funding}

Funding of the study came from Swedish International Development Cooperation Agency (Sida) through bilateral cooperation with Muhimbili University of Health and Allied Sciences (MUHAS), Tanzania and Uppsala University (UU) and Karolinska Institutet (KI), Sweden. The funders played no role in the design, data collection, analysis, interpretation or writing of this study.

\section{Authors' contributions}

All authors were involved during the planning of this study. AS did all field activities with close supervision of MM, CH, SM and ABP. AS and ABP read the transcripts, did the initial coding, making categories and abstracting initial themes. Other authors reviewed and shaped the final themes. AS prepared the first draft. All authors read and approved the final manuscript.

\section{Acknowledgements}

Mtwara Regional Medical Officers, Regional RCHCos (Nurse Arope R), District RCHCos form study districts, facility managers, VA interviewers, Sida, Muhimbili University of Health and Allied Sciences (MUHAS), Uppsala University.

\section{List Of Abbreviations}




\begin{tabular}{ll} 
MDSR & Maternal Death Surveillance and Response \\
\hline MoHCDGEC & Ministry of Health Community Development Gender Elderly and Children \\
\hline MMR & Maternal Mortality Ratio \\
\hline RHMT & Regional Health Management Team \\
\hline RRCHCo & Regional reproductive and Child Health Coordinator \\
\hline SA & Social Autopsy \\
\hline SDGs & Sustainable Development Goals \\
\hline VA & Verbal Autopsy \\
\hline WHO & World Health Organization
\end{tabular}

\section{References}

1. World Bank, Trends in maternal mortality 2000 to 2017 : Estimates by WHO, UNICEF, UNFPA, World Bank Group and the United Nations Population Division. 2019, World Bank Group: Washington, D.C. p. http://documents.worldbank.org/curated/en/793971568908763231/Trends-in-maternal-mortality2000-to-2017-Estimates-by-WHO-UNICEF-UNFPA-World-Bank-Group-and-the-United-Nations-Population-Division.

2. United Nations, The Millennium Development Goals Report, C. Way, Editor. 2015: New York.

3. Kassebaum et al., Global, regional, and national levels and causes of maternal mortality during 1990-2013: a systematic analysis for the Global Burden of Disease Study. Lancet, 2013. 384: p. 980-1004.

4. Ministry of Health Community Development Gende Elderly and Children - MoHCDGEC/Tanzania Mainland, et al., Tanzania Demographic and Health Survey and Malaria Indicator Survey 2015-2016; Key Indicators, M. MoHCDGEC, NBS, OCGS, and ICF, Editor. 2016: Dar es Salaam, Tanzania.

5. Ministry of Health and Social Welfare, Maternal and Perinatal Death Surveillance and Response guideline. 2015, Dar es Salaam: Reproductive and Child Health section.

6. WHO, Maternal death surveillance and response. Technical guidance. Information for action to prevent maternaldeath. 2013 : 20 Avenue Appia, 1211 Geneva 27.

7. WHO, WHO Technical Consulation on Verbal autopsy Tools. Final Report, WHO, Editor. 2005 Department of Measurement and Health Information Systems. Evidence and Information for Policy: Geneva.

8. WHO, Beyond the Numbers; Reviewing maternal deaths and complications to make pregnancy safer. 2004, Geneva: World Health Organization. 142.

9. Kalter, H.D., Salgado, R., Babille, M., Koffi, A.K., and Black, R.E., Social autopsy for maternal and child deaths: a comprehensive literature review to examine the concept and the development of the method. Population Health Metrics, 2011. 9(45): p. doi:10.1186/1478-7954-9-45.

10. WHO Social autopsy as an intervention tool in the community to prevent maternal and neonatal deaths: experiences from Bangladesh. 2018. http://mdsraction.net/case-studies/social-autopsy-as-an-intervention-tool-in-the-community-to-prevent-maternal-andneonatal-deaths-experiences-from-bangladesh/.

11. Singh, S., Murthy, G.V.S., Thippaiah, A., Upadhyaya, S., Krishna, M.,Shukla, R., and Srikrishna, S.R., Community Based Maternal Death Review: Lessons Learned from Ten Districts in Andhra Pradesh, India. Maternal and Child Health Journal, 2015. 19(7): p. 1447-1454.

12. Bayley, O., Chapota, H. et al Community linked maternal death review (CLMDR) to measure and prevent maternal mortality: a pilot study in rural Malawi. BMJ Open, 2015. 5(4).

13. Biswas, A., Social autopsy: A social intervention to explore social barriers and errors behind maternal deaths due to pre-eclampsia/eclampsia and haemorrhage in rural Bangladesh 2015: p. https://www.researchgate.net/publication/283325181.

14. Mahmud, R., Sohel, H.A., Sharif, M., Kuppens, L., Rakhimdjanov, S., Sayem, A.S.M., Khan, M., \& Biswas, A., Social autopsy triggers community response for averting maternal and neonatal death in Bangladesh: Experience from 'Maternal and Perinatal Death Review in 10 Districts. World Health Organization.., 2016: p. 1-5 Available from: http://www.who.int/maternal_child_adolescent/epidemiology/maternal-death-surveillance/case-studies/social-autopsybangladesh/en/.

15. D'Ambruoso, L., et al., A lost cause? Extending verbal autopsy to investigate biomedical and socio-cultural causes of maternal death in Burkina Faso and Indonesia. Soc Sci Med, 2010. 71(10): p. 1728-38.

16. Fantaye, A.W., et al., A qualitative study of community elders' perceptions about the underutilization of formal maternal care and maternal death in rural Nigeria. Reproductive Health, 2019. 16(1): p. 164.

17. Mairiga, A., M. Kawuwa, and A. Kullima, Community Perception of Maternal Mortality in Northeastern Nigeria. African journal of reproductive health, 2009. 12: p. 27-34.

18. Adegooke, A.A., et al., Community perceptions of the causes and prevention of maternal mortality. African Journal of Midwifery and Women's Health, 2010. 4(1): p. 23-29.

19. Said, A., et al., Causes of maternal deaths and delays in care: comparison between routine maternal death surveillance and response system and an obstetrician expert panel in Tanzania. BMC Health Services Research, 2020. 20(1): p. 614.

20. United Republic of Tanzania URT, 2012 Population and Housing Census: Population Distribution by Administrative Areas. 2013, National Bureau of Statistics, Ministry of Finance, Office of Chief Government Statistician President's Office, Finance, Economy and Development Planning Zanzibar: Dar es

Loading [MathJax]/jax/output/CommonHTML/jax.js 
21. World Health Organization, Verbal autopsy standards: The 2016 WHO verbal autopsy instrument. 2016, Geneva: World Health Organization

22. Thaddeus, S., and D. Maine, Too far to walk: maternal mortality in context. Soc Sci Med, 1994. 38(8): p. 1091 - 1110.

23. Butina, M., A Narrative Approach to Qualitative Inquiry. American Society for Clinical Laboratory Science, 2015. 28(3): p. 190-196.

24. Creswell, J.W., Qualitative Inquiry and Research Design: Choosing Among Five Approaches. 2012: SAGE Publications.

25. ljang, Y.P., et al., Awareness and practice of birth preparedness and complication readiness among pregnant women in the Bamenda Health District, Cameroon. BMC Pregnancy and Childbirth, 2019. 19(1): p. 371.

26. Bintabara, D., et al., Birth preparedness and complication readiness among recently delivered women in chamwino district, central Tanzania: a cross sectional study. Reproductive Health, 2015. 12(1): p. 44.

27. Urassa, D.P., A.B. Pembe, and F. Mganga, Birth preparedness and complication readiness among women in Mpwapwa district, Tanzania. Tanzan J Health Res, 2012. 14(1): p. 42-7.

28. Berhe, A.K., et al., Birth preparedness and complication readiness among pregnant women in Ethiopia: a systematic review and Meta-analysis. Reproductive Health, 2018. 15(1): p. 182.

29. August, F., et al., Birth preparedness and complication readiness - a qualitative study among community members in rural Tanzania. Global Health Action, 2015. 8(1): p. 26922.

30. WHO, World Health Report 2010. Health systems financing: the path to universal coverage. 2010: Geneva.

31. Upadhyay, P., et al., Influence of family members on utilization of maternal health care services among teen and adult pregnant women in Kathmandu, Nepal: a cross sectional study. Reproductive Health, 2014. 11(1): p. 92.

32. Pembe, A.B., et al., Qualitative study on maternal referrals in rural Tanzania: Decision making and acceptance of referral advice. African journal of reproductive health, 2008. 12: p. 120-31.

33. Omole, F.S., et al., Interacting with patients' family members during the office visit. Am Fam Physician, 2011. 84(7): p. 780-4.

34. Anderson, R.J., et al., Communication between healthcare professionals and relatives of patients approaching the end-of-life: $A$ systematic review of qualitative evidence. Palliative Medicine, 2019. 33(8): p. 926-941.

35. Committee on Family Caregiving for Older Adults; Board on Health Care Services, et al., Family Caregivers' Interactions with Health Care and Long-Term Services and Supports, ed. E.J. Schulz R. Vol. 8. 2016, Washington (DC): National Academies Press (US.

36. Madula, P., et al., Healthcare provider-patient communication: a qualitative study of women's perceptions during childbirth. Reproductive Health, 2018. 15(1): p. 135.

37. Mselle, L.T., T.W. Kohi, and J. Dol, Humanizing birth in Tanzania: a qualitative study on the (mis) treatment of women during childbirth from the perspective of mothers and fathers. BMC Pregnancy and Childbirth, 2019. 19(1): p. 231.

38. Webber, G., B. Chirangi, and N. Magatti, Promoting respectful maternity care in rural Tanzania: nurses' experiences of the "Health Workers for Change" program. BMC Health Services Research, 2018. 18(1): p. 658.

39. Miller, S. and J.M. Belizán, The true cost of maternal death: individual tragedy impacts family, community and nations. Reproductive Health, 2015. 12(1): p. 56.

40. Molla, M., et al., Impacts of maternal mortality on living children and families: A qualitative study from Butajira, Ethiopia. Reproductive Health, 2015. 12(1): p. S6.

\section{Supplementary Files}

This is a list of supplementary files associated with this preprint. Click to download.

- FilledSRQRChecklist.docx 